\title{
Increasing Capacity for Experiential Rotations for Pharmacy Learners: Lessons Learned from a Multisite Teaching Hospital
}

\author{
Karen Cameron, Olavo Fernandes, Emily Lap Sum Musing, and Colette Raymond
}

\section{INTRODUCTION}

A cross Canada, faculties of pharmacy are at various stages of implementing the joint recommendation of the Association of Faculties of Pharmacy of Canada and the Association of Deans of Pharmacy of Canada that entry-to-practice PharmD (EPPD) programs be in place for all faculties of pharmacy by $2020{ }^{1}$ This degree change is being implemented to ensure that pharmacy graduates have the skills to practise in the current health care environment, which calls for a more interprofessional, patientfocused role and an expanded scope of practice (including prescribing and vaccine administration). ${ }^{1}$ Curricular changes associated with the EPPD include an increase in the experiential rotation time from the 16 weeks required in the Bachelor of Science in Pharmacy (BScPhm) program to 40 weeks in the EPPD program. ${ }^{2}$ This article describes the processes followed and lessons learned during restructuring of traditional experiential education at the largest hospital site for the EPPD of the Leslie Dan Faculty of Pharmacy, University of Toronto, from the perspective of education coordinators at the University Health Network (UHN), an academic health care organization in Toronto, Ontario. Pharmacy education coordinators provide oversight for all pharmacy education occurring within a hospital pharmacy department, liaise with educational institutions, and optimize learner success.

The UHN comprises 4 health care facilities: 2 acute care inpatient hospitals, a cancer centre, and a multisite rehabilitation institute. The pharmacy department consists of about 125 fulltime equivalent pharmacists and 120 pharmacy technicians, who provide services to about 1300 inpatient beds and multiple ambulatory clinics and who operate 5 outpatient pharmacies.

Historically, the UHN has offered experiential education for different types of pharmacy learners, including technicians and undergraduate and graduate students. Before 2014, experiential rotations for pharmacy learners had some of the drawbacks associated with traditional pharmacy education, including short duration ( $\leq 4$ weeks); complex orientation to a new site with each rotation; "observership" time, which lacked meaningful patient care activity or personal accountability for patient care; and close supervision by a pharmacist preceptor, with a 1:1 learner to preceptor ratio for most rotations. ${ }^{3}$ The literature describes some strategies for expanding rotations, including use of pharmacy learners as pharmacist "extenders" in a layered learning model, ${ }^{4}$ development of a clinical teaching unit, ${ }^{5}$ and moving to year-round, programspecific rotations. ${ }^{6}$

\section{DESCRIPTION OF THE PROGRAM}

\section{Curricular Change}

The number of weeks of experiential education completed by pharmacy graduates has increased rapidly in recent years. Historically, the Leslie Dan Faculty of Pharmacy at the University of Toronto offered a BScPhm program with 16 weeks of experiential education (known as the Structured Practical Experience Program [SPEP]), which traditionally included up to 8 weeks in a hospital setting. ${ }^{7}$ In 2011, the EPPD was launched. In this program, learners are required to participate in 8 weeks of Early Practice Experience (EPE) and 36 weeks of Advanced Pharmacy Practice Experience (APPE) rotations. The APPE rotations include 10 weeks in hospital practice $(2 \times 5$-week rotations $), 10$ weeks in community pharmacy practice $(1 \times 10$-week rotation), and 5 weeks in an additional direct patient care setting (hospital inpatient, ambulatory, or community). Two 5-week electives (more direct or non-direct patient care rotations), and a 1-week "Transition to APPE" course complete the rotations. ${ }^{8}$ At the same time, up to 32 learners in the last 3 years of the $\mathrm{BScPhm}$ program transitioned to a combined $\mathrm{BScPhm} / \mathrm{Ph}$ armD program, which gave them the opportunity to earn both a BScPhm and a postbaccalaureate PharmD degree. Traditional postbaccalaureate PharmD learners (7-14 in number) were present in the class 
This single copy is for your personal, non-commercial use only.

For permission to reprint multiple copies or to order presentation-ready copies for distribution, contact CJHP at cjhpedit@cshp.ca

Table 1. Curricular Change at the Leslie Dan Faculty of Pharmacy, University of Toronto , $^{2,-10}$

\begin{tabular}{|c|c|c|c|c|c|c|}
\hline Program & Structure & $\begin{array}{l}\text { No. of Students } \\
\text { per Class }\end{array}$ & Time Frame & $\begin{array}{l}\text { Total Experiential } \\
\text { (weeks) }\end{array}$ & $\begin{array}{l}\text { Hospital } \\
\text { Rotation } \\
\text { (weeks)* }\end{array}$ & $\begin{array}{l}\text { Timing of } \\
\text { Rotations }\end{array}$ \\
\hline$\overline{\mathrm{BScPhm}}$ & $\begin{array}{l}1 \text { year prerequisite } \\
+4 \text {-year pharmacy } \\
\text { program }\end{array}$ & 240 & $\begin{array}{l}\text { Last class } \\
\text { graduated } \\
\text { June } 2014\end{array}$ & 16 weeks & Up to 8 weeks & $\begin{array}{l}\text { January to April } \\
\text { of each year } \\
\text { (ending in 2014) }\end{array}$ \\
\hline $\begin{array}{l}\text { Combined } \\
\text { BScPhm/PharmD }\end{array}$ & $\begin{array}{l}\text { Learners already } \\
\text { enrolled in BScPhm } \\
\text { program given } \\
\text { option to transition } \\
\text { to complete } \\
\text { postbaccalaureate } \\
\text { PharmD as well }\end{array}$ & $35-45$ & $\begin{array}{l}\text { Pogram ran for } \\
3 \text { years, classes } \\
\text { graduated } \\
\text { May 2013, } \\
\text { May 2014, } \\
\text { and May } 2015\end{array}$ & $\begin{array}{l}49 \text { weeks } \\
(1 \times 4 \text {-week } \\
\text { foundation rotation } \\
\text { plus } 9 \times 5 \text {-week } \\
\text { APPE rotations) }\end{array}$ & $\begin{array}{l}\text { Minimum } \\
20 \text { weeks }\end{array}$ & $\begin{array}{l}\text { January + May } \\
\text { through August + } \\
\text { November through } \\
\text { April (rotations } \\
\text { started in January } 2010 \\
\text { and ended in } \\
\text { May 2015) }\end{array}$ \\
\hline $\begin{array}{l}\text { Entry-to-practice } \\
\text { PharmD }\end{array}$ & $\begin{array}{l}2 \text { years prerequisite } \\
+4 \text {-year pharmacy } \\
\text { program }\end{array}$ & 240 & $\begin{array}{l}\text { First class } \\
\text { graduated } \\
\text { June } 2015\end{array}$ & $\begin{array}{l}44 \text { weeks } \\
\text { (8 weeks EPE, } \\
36 \text { weeks APPE), } \\
\text { which includes a } \\
\text { 1-week "Transition } \\
\text { to APPE" course }\end{array}$ & $\begin{array}{l}\text { Minimum } \\
10 \text { weeks }\end{array}$ & $\begin{array}{l}\text { Year-round: } \\
\text { APPE rotations } \\
\text { started in May } 2014 \\
\text { and are ongoing }\end{array}$ \\
\hline
\end{tabular}

APPE $=$ Advanced Pharmacy Practice Experience, EPE = Early Practice Experience.

*These rotations are conducted in multiple hospitals in multiple cities.

along with those in the combined degree program. About 40 pharmacy learners from this 5 -year combined BScPhm/PharmD program each completed 44 weeks of rotations, 20 of those weeks at the same hospital rotation site (Table 1)., ${ }^{2,-10}$ With both of these new programs (combined BScPhm/PharmD and EPPD), the bulk of rotations took place in teaching hospitals affiliated with the University of Toronto, which also contributed to the need for expanded rotation availability at the UHN.

\section{Planning for Increased Capacity for Pharmacy Experiential Education at Local Hospitals}

In 2010, the Leslie Dan Faculty of Pharmacy formed the Hospital University Pharmacy Education Committee (HUPEC), which comprised faculty representatives and local hospital pharmacy directors from institutions that had formal teaching agreements with the university. The committee was chaired by the Associate Dean, Education, and its purpose was to determine how to increase experiential learner capacity. The education coordinators at hospitals within the Toronto Academic Health Science Network (TAHSN), faculty leaders, and representatives of the faculty's Office of Experiential Education formed a separate committee to operationalize HUPEC and Faculty of Pharmacy recommendations at the hospital sites. By 2013, detailed and specific agreements between the Leslie Dan Faculty of Pharmacy and local hospital pharmacy leadership had been developed in preparation for the new EPPD rotations. Key negotiation points included the number of rotations to be offered, resources for additional education coordinator time, pharmacist staffing, preceptor development programs, learner remediation programs, and workspace and computer facilities for learners. A collaborative set of transformational guiding principles was agreed upon (Box 1). The HUPEC met regularly during the transition years (2010-2013) and, at the time of writing, was continuing to meet quarterly to monitor the impact of rotations on participating hospitals and to plan for future years. The hospitals' education coordinators and the Office of Experiential Education committee continues to meet bimonthly to share information, report on struggles and successes, and plan for the future.

In the year leading up to initiation of the combinedprogram and EPPD rotations, pharmacy leaders and education coordinators held discussions with front-line pharmacists at the UHN hospitals to generate ideas on how to increase the number of pharmacy learners on site and how best to incorporate these learners into pharmacist workflow and teams.

\section{Implementation of an Institution-Specific Pharmacy Department Teaching Guideline}

UHN is a teaching hospital within the TAHSN, and there is a general expectation that all departments will offer rotations to learners. In 2012, a pharmacy-wide change management plan was used to create an institution-specific pharmacy department teaching guideline, which set a mandatory minimum teaching expectation for all pharmacists of $8-10$ weeks of preceptorship annually. The teaching guideline formed the basis for ensuring that all pharmacists would participate in preceptorship to the same minimum expected level, a requirement that has been incorporated into the department's annual performance review for pharmacists. In addition, because the Leslie Dan Faculty of Pharmacy has structured its rotations so that learners are available for year-round rotations, preceptors are encouraged to incorporate learners into their regular workflow, rather than taking prolonged periods away from patient care activities for teaching (e.g., lengthy discussions focused on general therapeutics); the latter approach may be possible when learners are on site for designated times, but is not suitable on an ongoing, sustainable basis. Scheduling of pharmacists in relation to rotations was also modified, such that the practice of avoiding vacation, weekend, or evening shifts during teaching was no longer a 
Box 1. Collaborative Guiding Principles for Advanced Pharmacy Practice Experience (APPE)*

- Evidence-informed process to select specific standardized patient care activities for APPE learners

- Formal pharmacy learner training programs for specific services (e.g., certification or validation processes for selected care activities)

- Integration of structured near-peer or peer-assisted teaching models

- Exploration of measurement of learners' impact on patient care through clinical performance indicators

- Year-round learner rotations

- Extended duration of rotations

- Incorporation of tiered workflow and clinician responsibility schematics

${ }^{*}$ Agreed upon by hospital pharmacy leadership (directors and education coordinators) in the local academic health science network and the Leslie Dan Faculty of Pharmacy, University of Toronto.

priority. Because learners are now more integrated within the team, other pharmacist staff members are able to assist with teaching and supervision during absences of the primary preceptor.

\section{STRATEGIES TO EXPAND EXPERIENTIAL EDUCATION FOR PHARMACY LEARNERS}

Since academic year 2011/2012, the UHN has employed several strategies across the pharmacy department at all sites to expand the number of pharmacy learners, to change the nature of the rotations, and to more completely incorporate learners into day-to-day activities, while striving to maintain the provision of meaningful patient care by learners and to shift preceptors away from traditional experiential education practices (Box 2). In 2011/2012, a total of 57 rotations were offered for SPEP, EPE, and PharmD learners, a number that increased to 197 for 2015/2016 (Figure 1). Pharmacy teams and preceptors have engaged pharmacy learners in numerous ways across the organization (Tables 2 and 3). In addition, various peer-to-peer and near-peer teaching strategies have been tried and established (Table 4). Similar strategies could be used by other organizations faced with increased demand for experiential rotations.

\section{Consider Efficient Orientation and Onboarding}

To minimize orientation time, pharmacy learners complete mandatory institution-specific orientation activities as independent electronic modules before the start of the rotation. Learners starting rotations at all UHN sites participate in a pharmacyspecific group orientation on their first day. The start dates of rotations for learners from all pharmacy faculties are aligned, to

\section{Box 2. Objectives of Experiential Rotations for Pharmacy Learners at the University Health Network, Toronto}

- To maximize experiential education for pharmacy learners through novel models of preceptorship.

- To ensure that learners who are receiving experiential education perform work that is meaningful to learning and to patient care.

- To expand and develop experiential preceptor capacity.

- To minimize time spent onboarding and orienting new pharmacy learners.

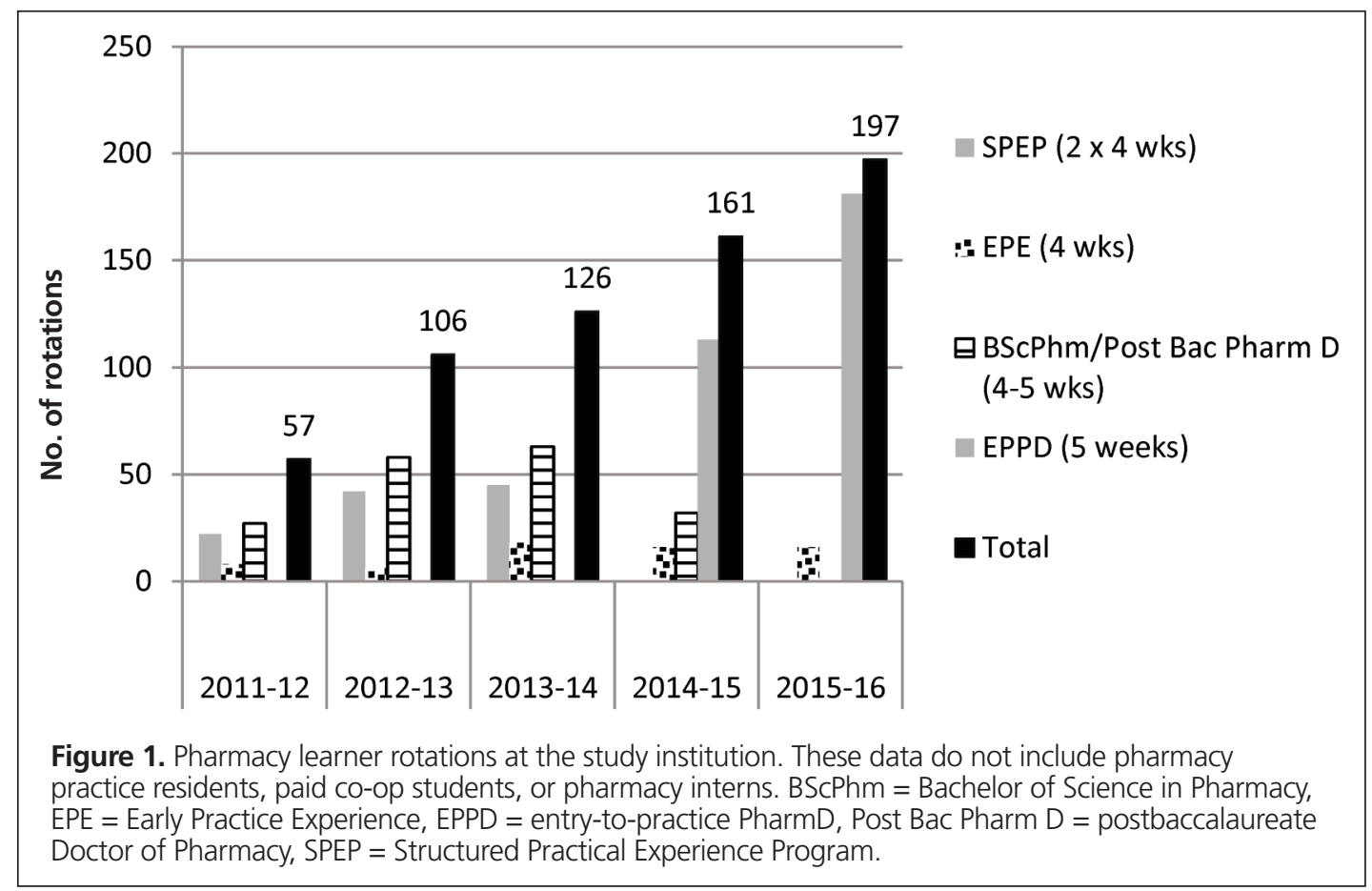


This single copy is for your personal, non-commercial use only.

For permission to reprint multiple copies or to order presentation-ready copies for distribution, contact CJHP at cjhpedit@cshp.ca

Table 2. Integration of Pharmacy Learners into Pharmacy Teams across Patient Care Sites

\begin{tabular}{|c|c|}
\hline Practice Setting & Learner Roles and Responsibilities, with Examples \\
\hline Surgery and preadmission clinic & $\begin{array}{l}\text { BPMH and medication reconciliation daily (morning: preadmission clinic) } \\
\text { Patient work-ups and care plans, with daily follow-up (afternoon: inpatient } \\
\text { surgical unit) }\end{array}$ \\
\hline Rehabilitation (2 learners) & $\begin{array}{l}\text { One learner Monday-Friday; plan for second learner Tuesday-Saturday } \\
\text { Admission BPMH and medication reconciliation } \\
\text { Discharge medication reconciliation }\end{array}$ \\
\hline Ambulatory chemotherapy day care & $\begin{array}{l}\text { BPMH and medication reconciliation } \\
\text { Chemotherapy and antiemetic education for patients } \\
\text { Patient call-backs (e.g., to ask about adverse effects, tolerability) } \\
\text { Checking and profiling of chemotherapy orders }\end{array}$ \\
\hline $\begin{array}{l}\text { Inpatient pharmacy team rotations (intensive care } \\
\text { unit, general medicine, nephrology; multiorgan } \\
\text { transplant and surgery; cardiology, coronary } \\
\text { care unit, cardiovascular intensive care unit; } \\
\text { general internal medicine; inpatient hematology } \\
\text { and oncology; palliative care; ambulatory } \\
\text { hemodialysis; family health team) }\end{array}$ & $\begin{array}{l}\text { One or two learners continuously within a team of } 10-20 \text { pharmacists, } \\
\text { with different areas of clinical practice focus within the team } \\
\text { BPMH and medication reconciliation } \\
\text { Interprofessional team rounds } \\
\text { Patient work-ups and pharmaceutical care plans } \\
\text { Patient and health professional education } \\
\text { Teaching and reviewing cases with other learners }\end{array}$ \\
\hline
\end{tabular}

$\overline{\mathrm{BPMH}}=$ best possible medication history.

\section{Table 3. Pharmacy Learner Activities in Non-Patient Care Rotations}

\begin{tabular}{|c|c|}
\hline Practice Setting & Learner Roles and Responsibilities, with Details of Rotation Logistics \\
\hline Teaching and education & $\begin{array}{l}\text { - Technician professional development: schedule and delivery } \\
\text { - Scheduling of medication reconciliation validation } \\
\text { - Provision of feedback to other pharmacy learners } \\
\text { - Provision of education to a pharmacy audience } \\
\text { - Education-related project work (e.g., literature searching, policy development, } \\
\text { scholarly writing) } \\
\text { - Residency-related project and planning work } \\
\text { - Meetings with local education coordinators and Office of Experiential } \\
\text { Education* staff }\end{array}$ \\
\hline Administration/leadership rotation & - Project work (e.g., scholarly writing, change management, presentations) \\
\hline Research or project & $\begin{array}{l}\text { - Participation in any component of a research project } \\
\text { - Drug-use evaluation (e.g., audits for venous thromboembolism or dangerous } \\
\text { abbreviations) } \\
\text { - Formulary alignments and submissions } \\
\text { - Data collection and analysis } \\
\text { - Protocol development }\end{array}$ \\
\hline Clinical trials & $\begin{array}{l}\text { - Protocol review } \\
\text { - Project work }\end{array}$ \\
\hline
\end{tabular}

*Within the Leslie Dan Faculty of Pharmacy, University of Toronto.

avoid the need to schedule additional orientation sessions. New pharmacy staff also participate in some aspects of the orientation. When possible, learners who completed the orientation during any previous rotation at the UHN are engaged to conduct this group session. To further reduce the significant time required for onboarding of new learners (orientation, providing access to computers and space, etc.), individual learners are scheduled for multiple rotations at the same site whenever possible. For 2015/2016, all learners in direct patient care rotations will complete a minimum of 10 weeks at one or more sites within the UHN.

\section{Reconsider the "Traditional Preceptorship Approach" to Rotations}

Through many collaborative discussions in various forums, front-line preceptors, pharmacy leadership, education coordinators, and the Office of Experiential Education debated and discussed the possibility of systematically encouraging movement away from a traditional, highly supervised rotation, with a 1:1 learner to preceptor ratio, toward more innovative approaches. As a result, the UHN has moved toward novel methods of preceptorship to increase its capacity for learner rotations, including peer-assisted and near-peer learning ${ }^{11}$ and consecutive rotations within a team or service area (Table 2). Near-peer and peer-assisted learning may involve several conformations of an attending pharmacist and multiple learners at different levels (e.g., pharmacy resident and student) or the same level (e.g., 2 APPE learners). ${ }^{11}$ In some examples of consecutive rotations within a team or service, 1 or 2 learners will have the same preceptor for the full 10 weeks (e.g., hemodialysis), whereas in other pharmacy teams (e.g., surgery, multiorgan transplant) the 10 -week rotation involves 2 preceptors within the same clinical area (possibly more, with weekend or evening preceptor coverage). Longer rotations allow learners to fully experience their 
Table 4. Peer Teaching Models

Rotation Site/Type and

Examples

Benefits

Teaching Model

\section{Ambulatory hemodialysis}

Pyramid (combination of senior Senior learners (pharmacy residents) mentor and junior learners), with activities geared to level of learner

Peer to peer $(2$ learners at the same level)

\section{General medicine}

10 -week rotation time frame ( $2 \times 5$-week rotations), with staggered rotation start dates 1 and 2. Learner B starts in block 2 and stays

for blocks 2 and 3, with learner A assisting with junior learners (APPE and/or EPE learners): e.g., EPE and APPE learners are supervised by a resident when doing BPMH. Resident reviews care plans before discussion with preceptor.

Two APPE learners divide patient workload and assist each other when needed. May encompass joint project work, review of care plans, and therapeutic discussions with preceptor.
- Residents gain teaching experience.

- Preceptor teaches topic once to larger group.

- Junior learners benefit from review before meeting with preceptor.

- Model facilitates collaborations across different classes of learners.

- Learners have peers with whom to discuss their ideas.

- Learners benefit from hearing about patients for whom others have done work-up.

Learner A starts in block 1 and stays for blocks

- Less requirement for preceptors to provide orientation with ongoing turnover of learners.

orientation and training of learner $\mathrm{B}$.

Learner $C$ starts in block 3 and stays for

blocks 3 and 4 , with learner B assisting with

orientation and training of learner $\mathrm{C}$; and so on.

Administration and leadership

Pyramid model (combination of junior and senior learners)

Multiple pharmacy residents, APPE learners, and often a pharmacist on a leadership sabbatical complete this rotation together.

Usually one major and several minor projects are completed. Discussions with learners and health care leaders are done as a group.

Preceptor teaches leadership principles to the group.

\section{Projects or research}

Peer to peer (2 learners at the same level)
More than one learner with research/project preceptor. Learners work on various aspects of a research project.
- Each meeting with institution leaders takes place only once, with a large group, rather than multiple times.

- Model facilitates completion of larger projects.

$\overline{\mathrm{APPE}}=$ Advanced Pharmacy Practice Experience, $\mathrm{BPMH}=$ best possible medication history, EPE = Early Practice Experience.

clinical areas of interest and contribute to learner confidence and competence in a given patient care area. Other benefits include an increase in learners' contributions to meaningful clinical activities and a reduction in preceptor burnout.

Learner independence and performance of meaningful patient care activities are encouraged within all rotations. ${ }^{6,12}$ After completing the usual coursework and "Transition to APPE" week, learners are expected to come to the start of each rotation practice-ready. Learners undergo "validation" to perform medication reconciliation, after which they are authorized to independently obtain best possible medication histories and conduct medication reconciliation at participating hospitals within the TAHSN. Encouraging and observing learner independence in meaningful patient care is a strong motivator for staff and promotes organizational support for teaching, which in turn also allows organizations to implement and/or sustain pharmacy services.

\section{Consider Nontraditional Rotations for Non-Patient Care Electives}

Learners have the option to take non-patient care electives, and other rotation types have been expanded accordingly, including teaching and education, patient safety, drug information, drug- use evaluation, research, and projects (Table 3). New preceptors for these rotations and new rotations are encouraged and supported through the education coordinators, clinical site leaders, managers, and directors.

\section{Communication between Preceptors and Education Coordinators Is Key}

With the increased number of experiential rotations, the role of the UHN education coordinators has changed, and these staff members now provide much more support to learners and preceptors on site. Frequent communication among the education coordinators, managers, and preceptors ensures adequate notification to preceptors about rotations and changes, as well as adequate onboarding, orientation, and resources for learners and preceptors. Ongoing communication ensures that expectations for both learners and preceptors are clear from the start of the rotation, that feedback and assessments occur on time, and that any issues of concern are identified early. The education coordinators communicate to the current preceptors weekly, more frequently if required.

The UHN education coordinators also communicate with preceptors, learners, pharmacy managers, interprofessional team members, faculty members, and faculty education coordinators 
with regard to identifying and managing learners who are struggling, cases of preceptor-learner mismatch, and other issues such as conflict within a team. The UHN education coordinators facilitate communication and feedback between preceptors and learners and also provide feedback to preceptors about their skills in setting expectations, communicating, and providing feedback. ${ }^{13}$

\section{Preceptor Development Is Important}

Preceptor training is an important consideration to ensure that preceptors are comfortable with the new curriculum and its graduates and to standardize approaches to assessment, learning styles, provision of feedback, and ways of dealing with struggling learners. The Leslie Dan Faculty of Pharmacy developed mandatory preceptor training modules, with input from the TAHSN education coordinators and preceptors. ${ }^{14}$ To facilitate completion of the preceptor development modules, the UHN education coordinators conducted and facilitated numerous local preceptor development training sessions (through both in-person delivery and recorded sessions). ${ }^{14}$ New preceptors are reminded that they must complete these rotations before precepting their first APPE student. UHN education coordinators and managers regularly meet with groups of preceptors at each site to discuss success stories, challenges, and common approaches. Resources, readings, and tools are shared broadly among preceptors. For example, because setting expectations is an important and expected part of experiential education, a generic lesson plan was created that aligns with the faculty's rotation assessment framework. This lesson plan, which includes rotation expectations, rounds schedule, rotation-specific activities, weekly target number of patients, and times for meetings for formative and summative feedback, can be modified by preceptors for their individual or team practice settings. This tool has been incorporated into the Leslie Dan Faculty of Pharmacy APPE manual. ${ }^{10}$

\section{Communication with the Faculty Is Key}

To maximize the number of rotations and to ensure rotation success, a close working relationship with the Leslie Dan Faculty of Pharmacy was essential. In the first year of the EPPD program, a variety of situations arose needing collaborative resolution, including schedule changes (for learner and preceptor reasons), learners who were struggling or failing, rotations that ended early, and last-minute requirements for supplemental or remedial rotations. A philosophy of flexibility and open communication between the site and the faculty's Office of Experiential Education was helpful in addressing these situations. In addition, ongoing meetings between the Office of Experiential Education and education coordinators from local area institutions and collaboration between hospital pharmacy directors and the Dean's office provided key support to ensure the sustainability of the experiential education program.

\section{CHALLENGES TO OVERCOME}

The change in approach to pharmacy learners that is evolving at UHN in relation to the EPPD program has led to important lessons learned.

\section{Early Hospital Exposure}

Since 2014, the focus for experiential education at both the Leslie Dan Faculty of Pharmacy and the teaching sites has been on APPE; as a result, fewer EPE rotations have been offered at the teaching hospitals, and the majority of pharmacy learners come to their APPE rotations with no prior hospital experience. Encouraging more hospital EPE rotations (which can occur at any hospital) is a future goal.

\section{Change Management for Preceptors and Learners}

Changing a culture takes longer than changing a process. ${ }^{15,16}$ Although many preceptors have attended training and many are experienced in this role, the cultural shift related to traditional learner-preceptor pharmacy education in the hospital setting is still in progress. Continual communication among education coordinators, pharmacy leadership, and the Leslie Dan Faculty of Pharmacy is required to maximize meaningful contributions to patient care by learners and to ensure that preceptors "let go" of highly supervised rotations.

\section{Early Planning}

Rotation offerings are due in November for the following academic year (which runs from May to April). As a result, many of the rotations offered do not indicate specific preceptors but rather identify the site and the clinical area (e.g., cardiology, multiorgan transplant). Inevitable adjustments due to learneror preceptor-related factors require flexibility and creativity in scheduling of rotations.

\section{Other Programs}

The UHN has an active pharmacy residency program, for which it must preserve its rotation and preceptor capacity. Residents have participated in near-peer and peer-assisted learning models, often in the capacity of senior learners. ${ }^{11}$ Residency programs like this one need to consider how to maintain rotation quality and expand rotation and preceptor capacity with EPPD learners alongside pharmacy residents. In addition, with the initiation of new PharmD bridging programs for practising pharmacists, a further increase in demand for PharmD rotations at the UHN is anticipated. The educational outcomes for these programs (set out by the Association of Faculties of Pharmacy of Canada) and for the EPPD are the same, so the rotation and preceptor pools at UHN are also the same. UHN also continues to offer experiential education for 
other types of learners (e.g., pharmacy technicians, researchers). The development of consistent educational policies and procedures and clear expectations for preceptors and learners assists in the management of so many learners.

\section{Support for Struggling Learners}

Having a larger number of learners inevitably means greater numbers of both excellent learners and learners who are struggling. Education coordinators and faculty members have found that they need to work hard to prevent learners from falling behind and to support those who are struggling, work that includes appropriate documentation and communication. The time and resources that faculty members and education coordinators devote to supporting preceptors and learners with rotation failure can be substantial. Careful planning, along with delivery and communication of a formal remediation plan, is important. $^{10}$

\section{CONCLUSION}

This article has described a transformative change within a large teaching hospital that allowed for a 3.5-fold increase over 4 years in rotation capacity for the EPPD. New experiential education strategies were implemented to focus pharmacists and learners on the delivery of consistent, high-quality, direct patient care services in conjunction with independent learner practice. Numerous preceptorship strategies have been engaged to continue expanding roles for APPE learners.

Future plans include capturing the meaningful patient care activities that learners perform, ${ }^{17}$ evaluating novel models of preceptorship, and increasing the capacity for inpatient and outpatient direct and non-direct patient care rotations across the UHN.

\section{References}

1. Position statement and joint resolution on the Doctor of Pharmacy (PharmD) for the first professional degree at universities in Canada. Association of Faculties of Pharmacy of Canada and Association of Deans of Pharmacy of Canada; 2010 Feb [cited 2015 Mar 6]. Available from: https://www.afpc.info/sites/default/files/AFPC_ADPC_PharmD_ Position_Statement_Resolution_Sept_2010.pdf

2. Accreditation standards for the first professional degree in pharmacy programs. Toronto (ON): Canadian Council for Accreditation of Pharmacy Programs; effective 2013 Jan [revised 2014 Jul; cited 2015 Jul 16]. Available from: www.ccapp-accredit.ca/site/pdfs/university/CCAPP_accred_ standards_degree_2014.pdf

3. Hall K, Musing E, Miller DA, Tisdale JE. Experiential training for pharmacy students: time for a new approach. Can J Hosp Pharm. 2012;65(4):285-93.

4. Delgado O, Kernan WP, Knoer S. Advancing the pharmacy practice model in a community teaching hospital by expanding student rotations. Am J Health Syst Pharm. 2014;71(21):1871-6.

5. Cox CE, Lindblad AJ. A collaborative approach to improving and expanding an experiential education program. Am J Pharm Educ. 2012;76(3):53.

6. Turner CJ, Ellis S, Giles J, Maffeo C, Hansen L, Saseen JJ, et al. A strategy to develop advanced pharmacy practice experiences. Am J Pharm Educ. 2007;71(3):46
7. Leslie Dan Faculty of Pharmacy degree comparison chart. Toronto (ON): University of Toronto, Leslie Dan Faculty of Pharmacy; 2015 [cited 2015 Mar 5]. Available from: http://pharmacy.utoronto.ca/pharmd/admissions/ program/degree-comparison-chart

8. PHM400H1 Transition to Advanced Pharmacy Practice Experience [course description, fourth-year curriculum]. In: 2015-2016 calendar. Toronto (ON): University of Toronto, Leslie Dan Faculty of Pharmacy; [cited 2015 Sep 23]. p. 50. Available from: http://pharmacy.utoronto.ca/sites/default/ files/upload/pharmd/2015-16\%20Faculty\%20Calendar.pdf

9. PharmD: Current students [web page]. Toronto (ON): University of Toronto, Leslie Dan Faculty of Pharmacy; [cited 2015 Mar 5]. Available from: http://pharmacy.utoronto.ca/pharmd/current-students

10. Advanced Pharmacy Practice Experience manual 2014-2015. Toronto (ON): University of Toronto, Leslie Dan Faculty of Pharmacy, Office of Experiential Education; [cited 2015 Mar 5]. Available fron: www.pharmacy.utoronto.ca/ sites/default/files/upload/office_experimental_education/APPE\%20 Manual_final\%20\%202014-2015\%20PDF.pdf

11. Leong C, Battistella M, Austin Z. Implementation of a near-peer teaching model in pharmacy education: experiences and challenges. Can J Hosp Pharm. 2012;65(5):394-8.

12. Fernandes O, Shojania KG. Medication reconciliation in the hospital: what, why, where, when, who, and how? Healthc Q. 2012;15 Spec No.:42-9.

13. Koons K, Sincavage S. Precepting skills for precepting challenges. J Am Pharm Assoc. 2012;52(6):e273-6.

14. Preceptor Development Program. Toronto $(\mathrm{ON})$ : University of Toronto, Leslie Dan Faculty of Pharmacy; [cited 2014 Dec 22]. Available from: www.pharmacy.utoronto.ca/content/preceptor-development-program-pdp

15. Bridges W. Managing transitions: making the most of change. 2nd ed. Cambridge (MA): Da Capo Press; 2003.

16. Golden B. Transforming healthcare organizations. Healthc Q. 2006;10 Spec No.:10-9.

17. Fernandes O, Gorman SK, Slavik RS, Semchuk WM, Shalansky S, Bussières JF, et al. Development of clinical pharmacy key performance indicators for hospital pharmacists using a modified Delphi approach. Ann Pharmacother. 2015;49(6):656-69.

Karen Cameron, BScPhm, ACPR, CGP, is Education Coordinator in the Department of Pharmacy, University Health Network, and Adjunct Lecturer, Leslie Dan Faculty of Pharmacy, University of Toronto, Toronto, Ontario.

Olavo Fernandes, BScPhm, ACPR, PharmD, FCSHP, is Director - Clinical with the Department of Pharmacy, University Health Network, and Assistant Professor, Leslie Dan Faculty of Pharmacy, University of Toronto, Toronto, Ontario.

Emily Lap Sum Musing, BScPhm, MHSC, ACPR, FSCHP, CHE, FACHE, is Executive Director, Department of Pharmacy, and Clinical Risk and Quality and Patient Safety Officer, University Health Network, and Associate Professor, Leslie Dan Faculty of Pharmacy, University of Toronto, Toronto, Ontario.

Colette Raymond, BSPharm, PharmD, MSc, was, at the time of writing, an Education Coordinator with the University Health Network, Toronto, Ontario. She is currently based in Winnipeg, Manitoba.

Competing interests: None declared.

\section{Address correspondence to:}

Karen Cameron

Pharmacy Department

University Health Network

Peter Munk Building, B-160

585 University Avenue

Toronto ON M5G 2N2

e-mail: Karen.cameron@uhn.ca 